\title{
A importância da ciência canônica em terras amazônicas
}

The importance of canonical science in amazonian lands

Efferson Andrade ${ }^{1}$

$\mathrm{Na}$ história jurídica eclesiástica, mesmo atritada pelo antijuridicismo de alguns pastoralistas, identifica-se a autonomia da Igreja como sociedade perfeita que se rege como toda sociedade organizada por leis ordenadas que, ao serem codificadas, almejam, em sua natureza e finalidade próprias, a justificação do direito canônico como regulador das relações entre as pessoas e instituições, ou seja, na vida e na ação da Igreja.

A história do direito eclesial concebe o ordenamento canônico como estrutura jurídica da Igreja, isto é, um sistema de relações jurídicas, mais do que um conjunto de normas. Adota-se o direito canônico como ciência porque ele possui objeto específico e uma peculiaridade científica na qual se realiza a singularidade dos seus instrumentos e dos seus recursos técnicos.

A Constituição Apostólica Veritatis Gaudium aponta o cerne da fé católica no mundo acadêmico, a fim de que, a partir do encontro pessoal com Jesus Cristo, compreendamos sua encarnação e a

\footnotetext{
${ }^{1}$ Mestrando em Direito Canônico pelo Instituto Superior de Direito Canônico de Santa Catarina. Graduado em Teologia pelo Instituto Santo Tomás de Aquino.
} 
natureza do Povo de Deus na Igreja Peregrina. A importância de fundamentar-se no Magistério da Igreja e na história visa transformar cada vez mais a educação acadêmica, produzindo com qualidade produtos inteligíveis e apreciativos.

Nisso, o Magistério da Igreja pós-conciliar desenvolveu seguramente a justificação do direito fundamentado no Concílio Vaticano II, pois esse, em parte, diante do mundo moderno, traz uma ruptura à sociedade eclesial e aos fiéis da Igreja, corrigindo algumas decisões históricas, sem deixar de sustentar e aprofundar sua íntima natureza e sua verdadeira identidade.

Essa identidade, na voz de Francisco na Exortação Apostólica "Querida Amazônia", tem um tom extremamente social, caracterizado pela defesa dos direitos humanos em que Cristo se identifica com os mais frágeis e pobres, exigindo assim que a sociedade eclesial, na relação evangelização e promoção humana, empenhe-se com o Reino de justiça.

Desse modo, o direito canônico norteia para indicar a estrada e sustentar a esperança do povo, como algo dinâmico e intrínseco no princípio transcendental e verdadeiramente divino do mistério da Igreja. Por isso, a ciência canônica, mesmo existindo uma aproximação com a teologia e com outras ciências, tem seus métodos próprios, visto sua autonomia e peculiaridade.

Alguns pensadores como Mörsdorf consideram o direito canônico como realidade teológica. Ele elabora, de modo positivo doutrinal, a fundação teológica do direito a fim de que o direito canônico seja incluído como um elemento essencial da Igreja e para promover a renovação da ciência do direito canônico na consciência da sua natureza teológica, já que, segundo Mörsdorf, o direito canônico está vinculado à vitalidade salvífica interna da Igreja. Para ele, o direito na Igreja não é meramente algo externo, mas está profundamente relacionado com os aspectos invisíveis do mistério da Igreja, até mesmo por participar da sacramentalidade dela própria.

Outro pensamento foi produzido em normas canônicas com a finalidade estreitamente pastoral e a natureza verdadeiramente jurídica 
do direito da Igreja. Assim como a Igreja não tem sentido em si mesma, existe para um fim: o de salvação; da mesma forma o direito na Igreja existe para a salvação, porém com um aspecto prático e pastoral que leva em conta, também, a historicidade da Igreja. Diferentemente, portanto, da teologia, enquanto meramente especulativa. Trata-se, por isso, de evitar teologizar indevidamente a legislação eclesiástica e juridicizar uma determinada teologia.

Assim, o direito canônico é apresentado como instrumento para a pastoral, constantemente atualizável. Sua função é regular e ordenar a pastoral. No documento sinodal isso reflexa numa Igreja amazônica pastoralista que cuida e fortalece os seus filhos com misericórdia, compreende, consola e integra, sem impor um conjunto de regras que julga e descarta.

No que se refere à vida e à atividade da Igreja, o ordenamento jurídico existe com função verdadeiramente pastoral na Igreja, pela ordem da caridade estabelecida pelo Evangelho, ou seja, promover a justiça. Mas a fundamentação da ciência canônica no mistério da Igreja não se apropria, nem na ciência pastoral, nem na disciplina teológica, visto que a ciência canônica é científica e expositiva.

A procura pela justiça, nas relações interpessoais dos fiéis e de instituições da Igreja, faz com que o jurista utilize método jurídico dentro da ciência canônica. Não são jurídicos por ser objeto de normas ou de disposições humanas, mas porque o objeto formal da ciência canônica é a relação social na Igreja vista sob a razão do justo, determinando, assim, o núcleo do próprio objeto: a Revelação.

Nesse sentido, podemos ver na exortação apostólica sobre a Amazônia que, dentro da diversidade dos locais, os acordos ou decisões ajuizadas tomam diversas soluções perante os problemas surgidos, revelando várias formas de organizações eclesiais. Essas soluções resultam no que Francisco aponta como "[...] num plano 
superior que conserva em si as preciosas potencialidades das polaridades em contraste."2.

Quando não se superam os desafios, resulta no descuido da oportunidade de exercitara indispensável tarefa de reconhecer os próprios limites e agarra-se a critérios que produzem juízos equivocados. Perdem-se valores incalculáveis, por aprisionar-se e priorizar a incompetência humanístico-existencial na diversidade dos ambientes, e retarda o processo de conversão por posturas enrijecidas que levam à crueldade dos preconceitos, ódios e indiferenças.

$\mathrm{Na}$ Exortação Apostólica Evangelii Gaudium, Francisco apontou os desafios da atualidade na dimensão social, cultural e econômica e, diante dessa realidade, a Igreja precisa ter a propriedade esperançosa na realidade comunitária, erradicando assim o individualismo, a crise de identidade, o declínio no fervor reproduzido nos cristãos como invejas, ciúmes e grandes rivalidades. Também apontou "a maior ameaça" que é "[...] o pragmatismo incolor da vida quotidiana da Igreja, no qual aparentemente tudo procede na faixa normal, quando na realidade a fé se vai desgastando." 3 .

Em tempos contemporâneos, em que se vive uma pluralidade de ideias e a mega valorização de uma cultura envolta em uma avalancha de complexas mudanças, com configuração de polarizações e extremismos inquietantes, a Evangelii Gaudium, iluminada pelo Espírito Santo, experimenta o indicativo incontestável de que reformar é necessidade urgente para abrir horizontes novos.

Essa tarefa, desejosa de fazer-se colaboradora do amor e da verdade, arquitetando uma era nova, exige a audácia de evoluir a consciência iluminada pela verdade do Evangelho e pela alegria de sair da própria prisão existencial, ou seja, "todos devemos deixar que os outros nos evangelizem constantemente", pois "a Igreja não

2 FRANCISCO. Adhortationes apostolicae: evangelii gaudium (24/XI/2013). In: $A A S$ 105, 2013, n. 228, p. 1019-1137.

${ }^{3}$ Ibid., n. 83 .

${ }^{4}$ Ibid., n. 12. 
evangeliza se não se deixa continuamente evangelizar"5. Isso é ter capacidade de promover dinâmicas, encontrar respostas e configurações evangelizadoras que tornem as comunidades eclesiais, decididas a inovar-se para anunciar com autenticidade a alegria do Evangelho, sempre a serviço da vida do povo.

Desse modo, pensar uma academia de ciência canônica na Amazônia é ecoar a voz de Francisco: "o Espírito Santo embeleza a Igreja, mostrando-lhe novos aspectos da Revelação e presenteando-a com um novo rosto. Trata-se, em última instância, de permitir e incentivar que o anúncio do Evangelho inexaurível, comunicado com categorias próprias da cultura onde é anunciado, provoque uma nova síntese com essa cultura." 6 .

A perspectiva de uma faculdade de direito canônico na Amazônia é a possibilidade desafiante do anúncio do Evangelho comunicado em uma nova linguagem parabólica na qual "Deus nos atrai, no respeito da complexa trama de relações interpessoais que a vida numa comunidade humana supõe."’ . Encontrar novos caminhos evangelizadores para transmitir o direito como sinal de pastoreio de uma Igreja, em saída, que tenha capacidade de ir ao encontro dos diversos "outros", pois "ninguém se salva sozinho, isto é, nem como indivíduo isolado, nem por suas próprias forças" ${ }^{\prime}$, conforme o exemplo relatado em Atos dos Apóstolos das primeiras comunidades cristãs, em que os crentes tinham um só coração e uma só alma. (At 4,32).

Pensar numa ciência canônica dentro da Pan-amazônica parte da coragem de "desenvolver o prazer espiritual de estar próximo da vida das pessoas, até chegar a descobrir que isto se torna fonte duma alegria superior" $"$ e de não apresentar algo que pese na vida dos fiéis,

${ }^{5}$ Ibid., n. 174.

6 FRANCISCO. Adhortationes apostolicae post-synodalis: Querida Amazônia (24/XI/2013), 68.

7 FRANCISCO. Adhortationes apostolicae: evangelii gaudium (24/XI/2013). In: $A A S$ 105, 2013, n. 113, p. 1019-1137.

${ }^{8}$ Ibidem.

${ }^{9}$ Ibid., n. 268. 
em razão dos diferentes ambientes culturais, mas sim, acolhedora, misericordiosa e facilitadora da casa paterna onde há lugar para todos.

Enfim, a partir da missão de promover uma comunhão dinâmica, aberta e missionária dentro da diversidade, pluralidade e multiplicidade dos fiéis para a vida eclesial proposta no Código de Direito Canônico, ${ }^{10}$ sonhar uma academia canônica no solo da Amazônia, à luz da Evangelii Gaudium, é um projeto de lei vasto e programático, sem particularismos, nem exclusivismos, que pode revelar a fecundidade da experiência das leis canônicas inseridas na evangelização dos povos amazônicos como paixão por Jesus, e simultaneamente uma paixão por aquele povo na promoção da vida humana na sociedade eclesial neste período histórico.

${ }^{10}$ Ibid., n. 31 . 